\title{
A novel voltage sag approach during unintentional islanding scenarios: A survey from real recorded events
}

\author{
Alexandre Serrano-Fontova ${ }^{1,2}$, P. Casals-Torrens ${ }^{1}$ and R. Bosch ${ }^{1}$ \\ ${ }^{1}$ Department of Electrical Engineering \\ E.T.S.E.I.B, Polytechnic University of Catalonia \\ Edifici H planta 2, Avda. Diagonal, 64708028 Barcelona (Spain) \\ ${ }^{2}$ Electrica Serosense Distribuidora \\ Pol. Ind. Panamà. Ctra. Nac. II Km. 450, 25110 Torres de Segre (Spain)
}

\begin{abstract}
In this paper, a new voltage sag approach is analytically modelled and validated using both simulation and field measurements. The main aspect of this approach is to propose a new voltage sag feature which appears during unintentional islanding operations (IOs). The unintentional IO occurs when an induction motor is removed from the main utility following a circuit breaker (CB) clearing, transiently, the induction motors (IMs) are acting as generators maintaining the affected distribution feeder with voltage until it is reconnected. The voltage sag modelled in the current article follows an exponential form, as a matter of fact, here it will be demonstrated that the proposed model reaches satisfactorily the field measurements and evidences the dependability of the model adopted. Furthermore, it is worthwhile to note that this novel power quality (PQ) event has not been investigated yet and enhances voltage sag studies. Lastly, it is crucial to point out that all recorded events and a large amount of data needed so as to validate this transient, has been measured in a distribution network (DN) located in Spain.
\end{abstract}

\section{Key words}

Power quality, islanding operations, voltage sags, distribution networks.

\section{Introduction}

The PQ has become a topic of undeniable scientific scrutiny due to the increasing use of sensitive equipment as well as the need for power supply continuity in both companies and end-users. In this sense, many attempts have been conducted in order to define and characterise the main features of the PQ. Particularly, within the range of PQ disturbances, voltage sags are defined as a decrease in the voltage between 0.1 to 0.9 p.u. in rms voltage at the rated frequency during between $0.1 \mathrm{~s}$ to $1 \mathrm{~s}$ [1]-[3]. Crucially, voltage sags are of utmost importance in the PQ studies and many efforts have been made so as to locate its origin [4], predicting its effects into loads and generators [5][6] [7]-[9]. Notwithstanding the foregoing, the load immunity is still under scientific study considering that same voltage sag deep and duration has different effects towards sensitive loads [10][11]. Voltage sags can be caused by numerous events such as, short-circuits, IM reacceleration [12], IM starting process [13], or sudden load connection. Against this background, voltage sags, generally, can be classified by its duration and deep [14]. In the early studies, voltage sags were considered rectangular, afterwards, it was found that a distinction between discrete and abrupt could be made in regards of its beginning and recovery considering multi-step recovery [15]. On the other hand, an interesting insight towards PQ studies is done when part of the grid is isolated from the main utility, conceptually known as IOs, therefore, the PQ in smart grids and isolated areas have reignited an undeniable fruitful debate [16]-[18]. Particularly in these scenarios, sensitive loads may undergo undesirable large and hazardous disturbances. Thereby, the detection and clearance of this unexpected IOs as stated in [19], is vital. Usually, IOs occur in presence of distributed generation (DG) resources, nonetheless, in the present approach, the aforementioned IO is caused by the IMs inertia following the loss-of-mains takes place, where one could expect an interruption [12].

In the present paper, a new voltage sag approach is proposed, its depth and duration depend on the rate between the induction motors rated power and the feeder loads, the type and value of the load torque applied to the IMs, on the preset reclosing time considered at the $\mathrm{CB}$ substation as well as on the type of fault. Moreover, this proposal enhances the currently available voltage sags modelling and further investigates the behaviour of this unexpected transient.

\section{Voltage sags review}

The general classification of voltage sags is thoroughly defined in [1]. Depending on the phases involved in the disturbance, its magnitude and its angle, the following classification is detailed in the next subsection. A comprehensive description of the voltage sags and its calculation is done in [20]. Since the nature of the faults is diverse, its recovery depends on the origin of the fault, and we can distinguish abrupt and discrete voltage sags. As commented earlier, voltage sags are characterized by its type, its duration, by its deep and finally by the phase angle jump. It is important to bear in mind that these parameters depend on the protective settings and also on the nature of the grid (e.g., mostly inductive or resistive). 
Firstly, abrupt voltage sags are ones who recover at the same instant, however, discrete voltage sags are those which recover with a time delay in different steps, see [21].

\section{A. Actual voltage sag classification}

According to [21], the following classification can be done:

- Asymmetrical voltage sags due to single-line-toground (SLG) short circuits (Type B), or due to phase-to-phase (L-L) short-circuits (Types C and D).

- Three-phase currents involved at the fault, symmetrical voltage sags (Type A) and doubleline-to-ground (L-L-G) short-circuits (E, F and G). This type recovers discrete with two steps, originating $\left(A_{1}, A_{2}, E_{1}, E_{2}, F_{1}, F_{2}, G_{1}\right.$ and $\left.G_{2}\right)$.

- Three-phase short-circuits which involve threephase and ground, originating a three-step recovering $\left(\mathrm{A}_{1}, \mathrm{~A}_{2}\right.$ and $\left.\mathrm{A}_{3}\right)$.

\section{Proposed voltage sag approach}

This section is aimed at describing the novel voltage sag modelling, purposefully, it will describe the analytical expression that follows once IM are removed from the grid. Since this type of disturbance is due to the IMs, it is essential to previously recall its equations before the fault (pre-fault) and during the disturbance.

The induction machine acting as a motor can be defined by this set of differential equations in the abc-reference frame (1):

$$
\left[\begin{array}{ll}
v s & a b c \\
v r & a b c
\end{array}\right]=\left[\begin{array}{cc}
R s & 0 \\
0 & R r
\end{array}\right]\left[\begin{array}{l}
i s a b c s \\
i r a b c
\end{array}\right]+\frac{d}{d t}\left[\begin{array}{l}
\phi s a b c \\
\phi s a b c
\end{array}\right]
$$

This equations can be expressed as dq by means of park transformation in stator reference (2):

$$
\begin{aligned}
& v_{s d}=\left(R_{s}+L_{s} \frac{d}{d t}\right) i_{s d}+M \frac{d i_{r d}}{d t} \\
& v_{s q}=\left(R_{s}+L_{s} \frac{d}{d t}\right) i_{s q}+M \frac{d i_{r d}}{d t} \\
& 0=\left(R_{r}+L_{r} \frac{d}{d t}\right) i_{r d}+M \frac{d i_{s d}}{d t}+L_{r}\left(\omega_{m} \wp\right) i_{r q}+M\left(\omega_{m \cdot} \cdot \wp\right) i_{s q} \\
& 0=\left(R_{r}+L_{r} \frac{d}{d t}\right) i_{r_{q}}+M \frac{d i_{r q}}{d t}-L_{r}\left(\omega_{m} \wp\right) i_{r d}-M\left(\omega_{m \cdot} \cdot \wp\right) i_{s d} \\
& \Gamma m-\Gamma r e s=J \frac{d \omega m}{d t} \\
& \omega m=\frac{d \theta m}{d t}
\end{aligned}
$$

where the subtitles $r$ and $s$ are referred to rotor and stator, $d \phi / d t$ is the flux linkage derivative, $v_{a b c}$ is the voltage vector and $i_{a b c}$ current vector, $M$ is the inductance matrix. The inductance matrix depends on rotor position $M(\theta)$. Note, however, that in a single-squirrel cage induction machine, both $v_{r d}$ and $v_{r d}$ are set to 0 .

It being understood that following $\mathrm{CB}$ disconnection from the main grid, the transient electromagnetic torque $T_{e m, I M}$ developed by the machine acting as a generator depends on the dynamic torque, load torque and friction torque, we have the following expression (4):

$$
\begin{aligned}
& T_{e m, I M}=f\left(T_{r}, T_{b}, J_{t}, \omega_{i m}\right) \\
& T_{e m, I M}=\frac{d \omega}{d t} J_{t}-\left(T_{r}+T_{b}\right)
\end{aligned}
$$

The decreasing IM speed is given hereunder (5):

$$
\frac{d \omega}{d t}=-\frac{\left(T_{r}+T_{b}\right)}{J_{t}}
$$

Accordingly, the mechanical power developed by the machine in the transient process is then computed as (6):

$$
P m_{i m}=T_{\text {em }} x \omega_{\text {im }}
$$

Thence, feeder loads act decelerating the IMs, thereby, its speed can be computed as (7):

$$
\frac{d \omega_{i m}}{d t}=\frac{\omega_{o}}{2 H_{i m}}\left[P m_{i m}-P e_{l o a d}\left(\delta_{i m}\right)\right]
$$

where the subscript im denotes that all values listed before are now referred to IM, $P e_{\text {load }}$ is referred to the power loads at the target feeder $H_{i m}$ is the IM inertia, $J_{t}$ is the sum of the IM inertia and the load inertia, $T$ is the electromagnetic torque developed by the machine acting as a motor, $T_{r}$ is the load torque, $T_{b}$ is the friction torque which will be considered as $0.056 \mathrm{Nm} \cdot \mathrm{s}$ and $T_{e m, I M}$ is the torque developed by the machine as acting as a generator.

\section{A. Voltage sag features}

Since the voltage sag parameters are $v_{s d}$ and $v_{s d}$ the stator voltages, by solving eq (2) considering no external excitation (CB has opened, the stator voltages will decay exponentially being represented by the form (8):

$$
V_{\text {sag }}(t)=V_{\text {pre }} \text { fault } \cdot t^{b} ; \quad \forall t \in\left[t_{i}, t_{f}\right]
$$

where $V_{s a g}(\mathrm{t})$ is the voltage sag temporal expression, $V_{\text {pre_fault }}$ is the pre-fault voltage value, $b$ is a nondimensional coefficient which depends on the activepower drawn by feeder loads. Given the natural tendency of the IM to decelerate due to the lack of grid supply, this coefficient has to be below zero. Thereby, this voltage sag approach can be characterised by;

- Its depth, which is represented by a non-constant retained voltage and, is given by (8).

- Its duration, which is dictated by the CB reclosing, commonly between $0.5 \mathrm{~s}$ and $1 \mathrm{~s}$. See, for instance, [22].

- Its recovery is based on a two-step recovery. Firstly, it takes place at the same instant when the $\mathrm{CB}$ recloses and secondly, the voltage recovers to the pre-fault voltage in few cycles due to the out of phase reclosing and IM reacceleration caused by the during the IO loss of speed. 


\section{Test system under investigation}

\section{A. Test system}

The test system used to perform this study is depicted in Fig. 1 , it is a radial DN fed from a HV/MV substation. Note that the system tested in this paper consists of two feeders, named $\mathrm{A}$ and $\mathrm{B}$ in Fig. 1, and connected to the HV/MV substation through Line 12. Therefore, the test system has 14 medium voltage (MV) nodes and 9 low voltage (LV) nodes. The short-circuit capacity measured at the HV terminal is 1000 MVA.

\section{B. Three-phase Matlab/Simulink model adopted}

The test system model has been implemented in the MATLAB/Simulink environment, taking advantage of the toolbox SimPowerSystem. The three-phase model implemented is showed in Fig. 8 and has been performed in a computer with a processor of $3.6 \mathrm{GHz} 8$-core Intel i7 and $8 \mathrm{~GB}$ of RAM. The simulation has been conducted in a discrete mode with a fixed sample time of $50 \cdot e-6 \mathrm{~s}$, the solver function used is ode 8 based on Dormand-Prince eight-order (RK8) formula and the simulation time for all scenarios consists of 2 s. See Fig. 2. All the simulations have been performed with a single line-to-ground (SLG) fault with a resistance fault of $5 \Omega$ at node 7 .

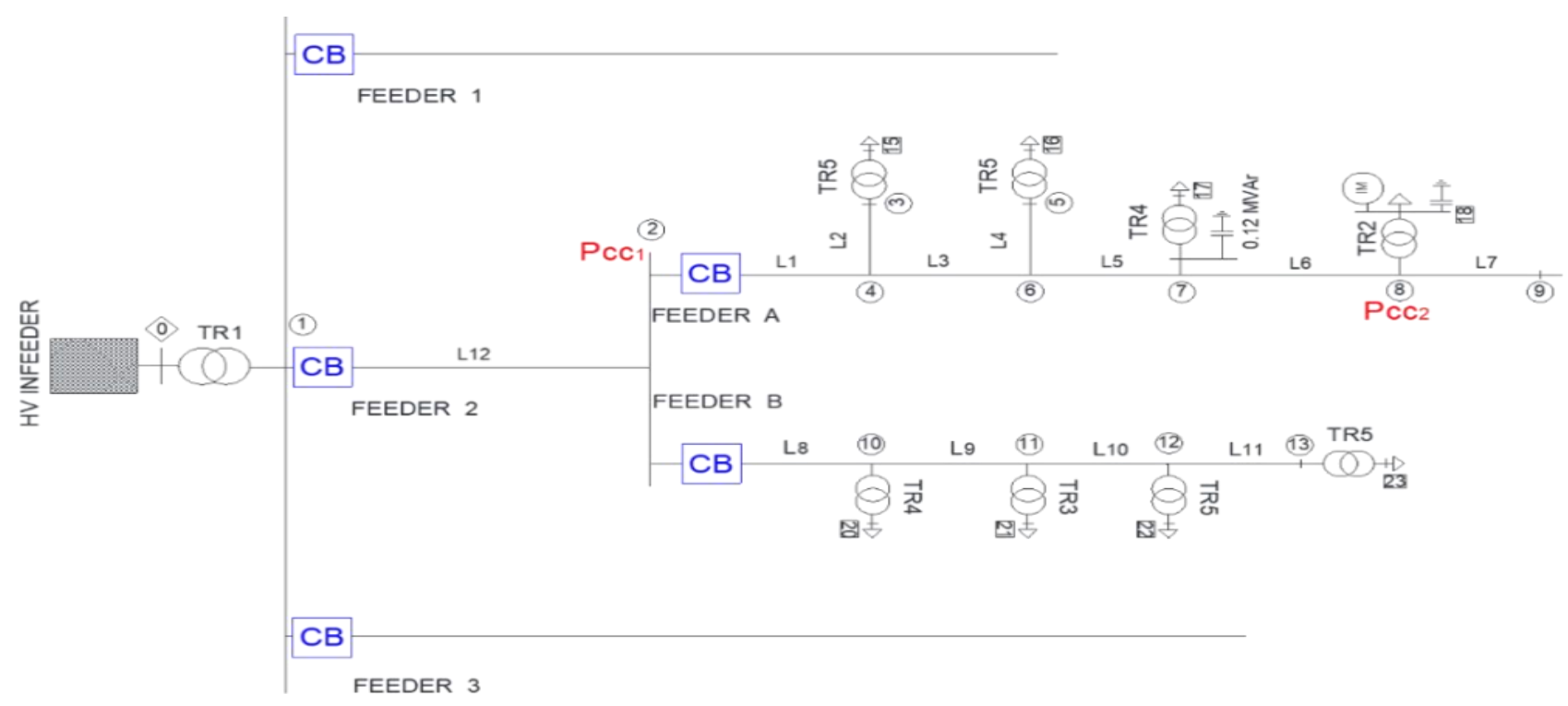

Fig.1. Test system under invetigation

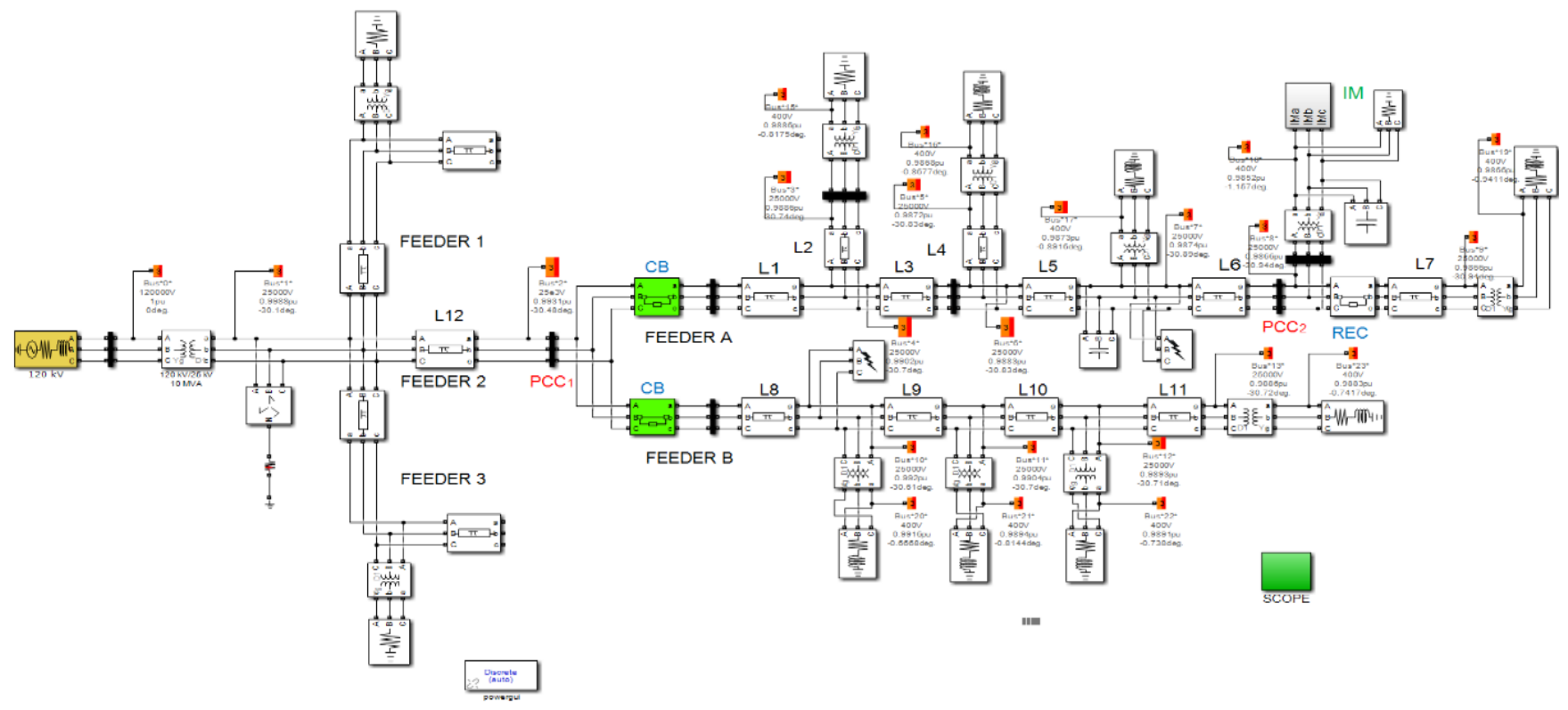

Fig.2. Three-Phase Matlab model adopted 


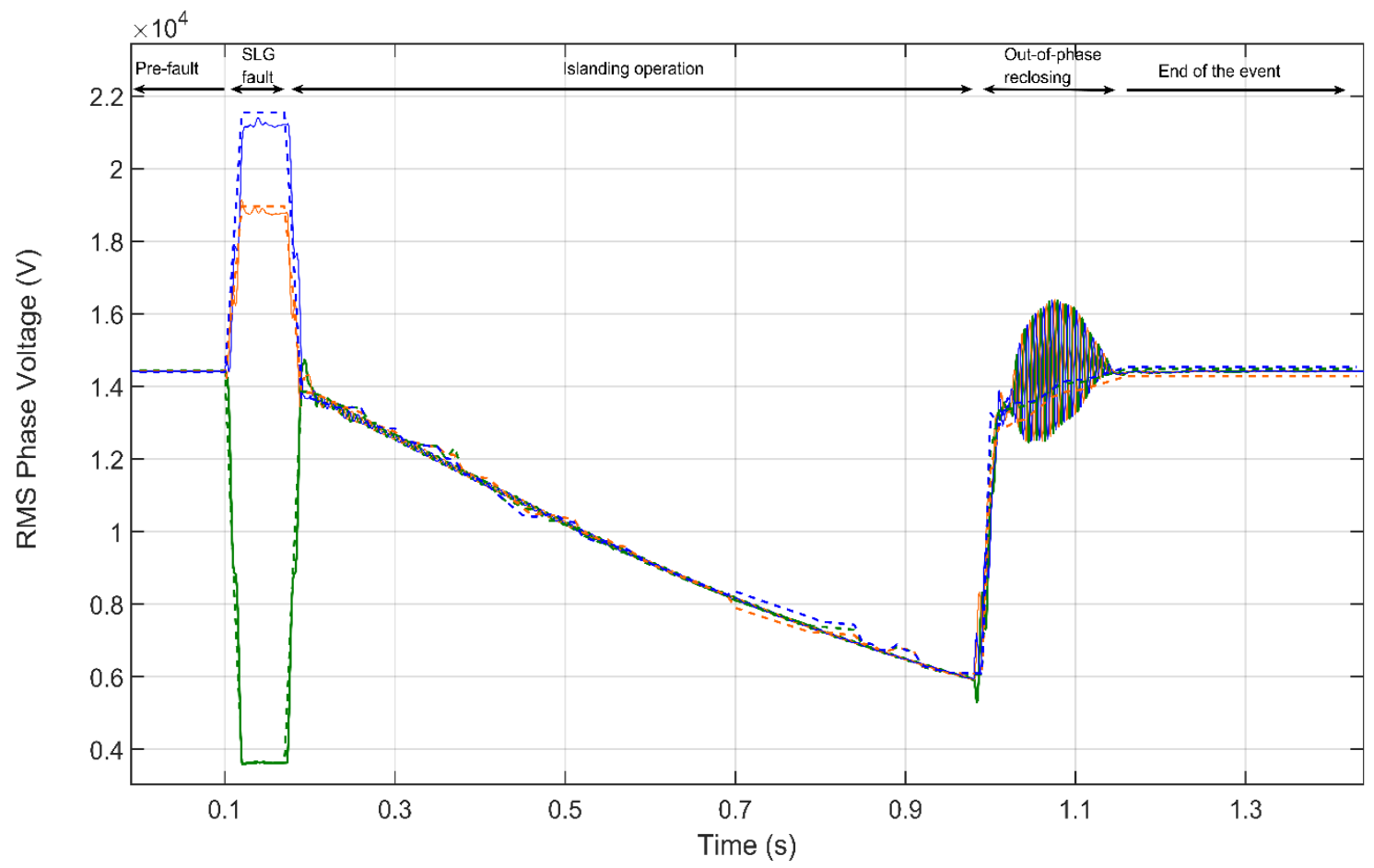

Fig.3 Model validation. (a) Frequency comparison, dashed-black (measurement), solid-black (simulation); (b) RMS Phase voltage comparison, solid (simulation) / dashed (measurements), orange (Phase A), blue (Phase B) and green (Phase C)

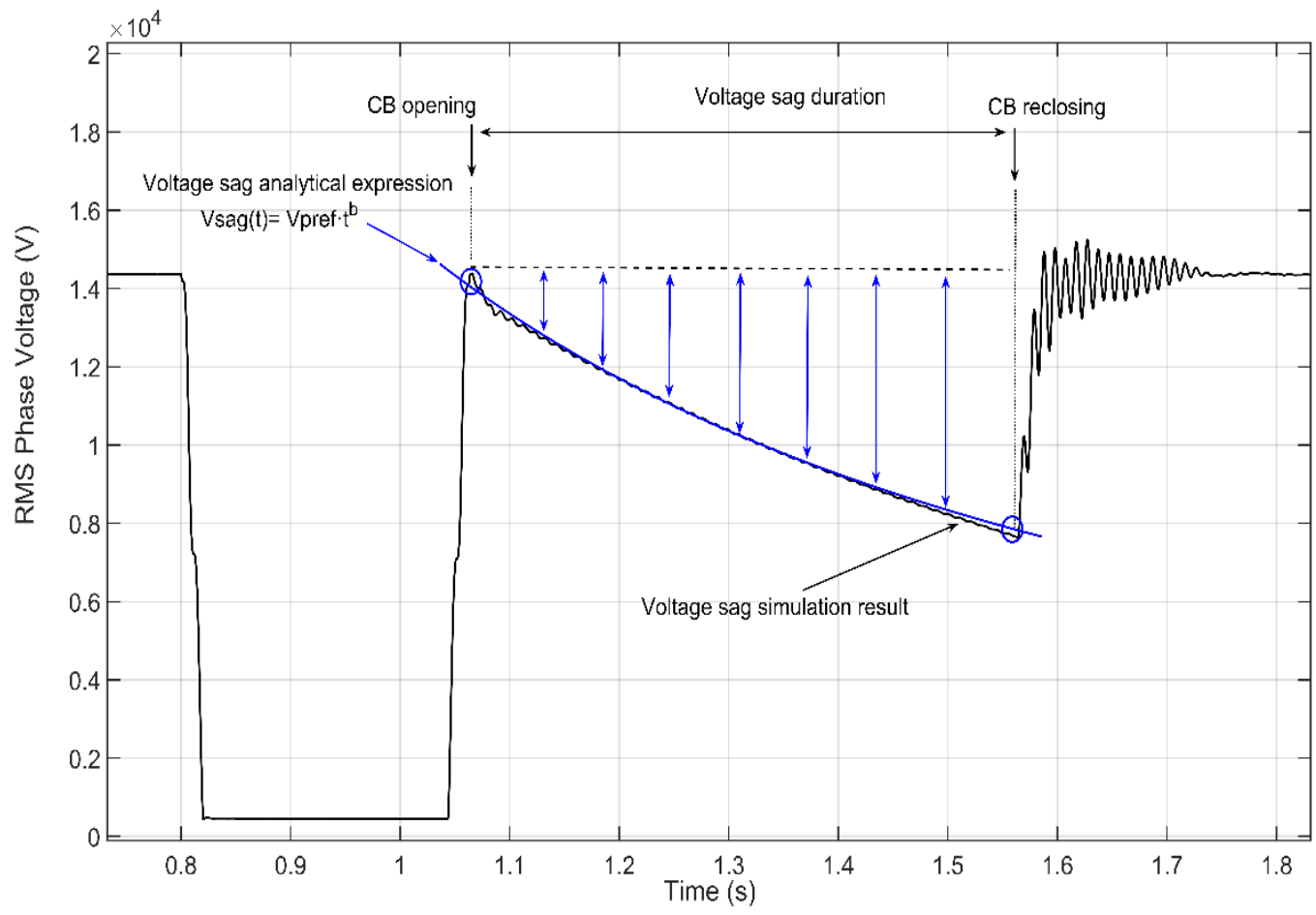

Fig. 4 Voltage sag deep for a given scenario

\section{Model validation and results discussion}

This section aims to show and further discuss the previously proposed voltage sag approach as well as validate the model adopted by comparing both simulation results with field measurements.

\section{A. Model validation}

This subsection seeks to address the model validation of the three-phase Matlab/Simulink model adopted in order to give maximum fidelity not only to the recorded field measurements but also to the proposed model. For brevity, the model validation will be made with one real event. Thus, in Fig. 3 the three-phase voltages for both simulation and field measurements are observable. 


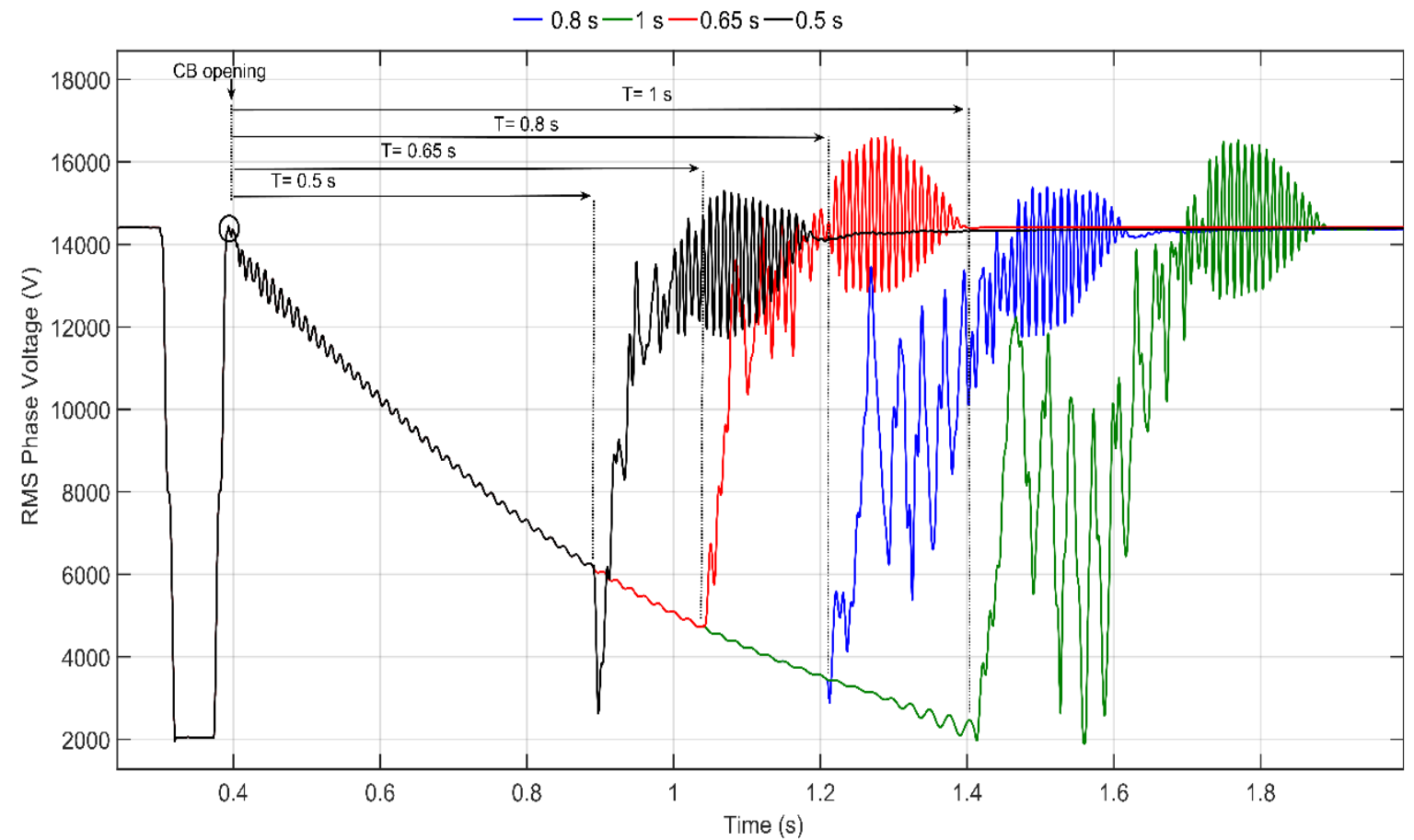

Fig. 5 Voltage sag duration for different $\mathrm{CB}$ reclosing times

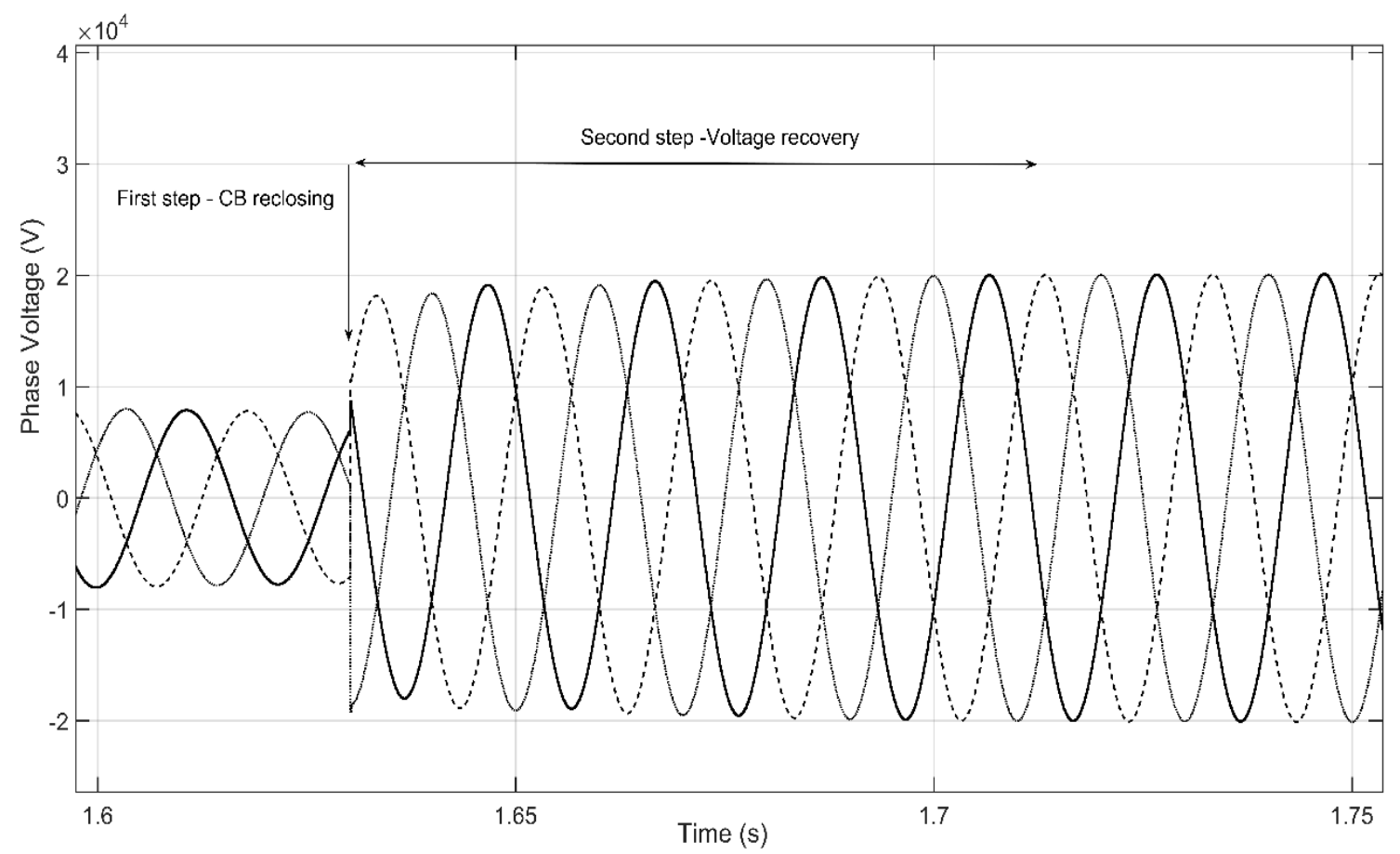

Fig. 6 Voltage sag recovery

From observing Fig. 3 it can be seen that a SLG occurs in the DN, and after $100 \mathrm{~ms}$ the fault is cleared, when the voltage sag begins. The voltage sag duration is $800 \mathrm{~ms}$, the recovery begins when the $\mathrm{CB}$ recloses the circuit at the same instant $(\mathrm{t}=1 \mathrm{~s})$ and ends $150 \mathrm{~ms}$ after when voltage is fully recovered at $(\mathrm{t}=1.15 \mathrm{~s})$.

\section{B. Simulation results and discussion}

In this subsection, several simulations will demonstrate the previously described voltage sag main features.
Regarding voltage sag deep, as an example, Fig. 4 shows the voltage sag obtained from simulations and the analytical form defined in subsection 3A. Simulations considered a $64 \mathrm{~kW}$ feeder loads value and the IM running empty at the time the fault occurs. As can be drawn from this Figure, the plotted curve fits the simulation results perfectly.

On the other hand, the voltage sag duration is in fact displayed in Fig.5, which unmistakably evidences the fact that voltage sags duration depends on the reclosing times implemented in the protective relays. 
Thirdly, the voltage recovery is plotted in Figure 6.

Simulations discussion is detailed down below for the voltage sag main characteristics;

\section{1) Voltage sag magnitude.}

Voltage sag magnitude as expected follows a negative exponential curve which slope depends on $b$. This means that, depending on the active-power feeder loads at the time the fault occurs, this parameter will vary. Particularly, in this case, $b$ proved to be -1.42 and the $\mathrm{CB}$ reclosing time $500 \mathrm{~ms}$.

\section{2) Voltage sag duration.}

From observing Figure 4, the duration can be seen for four different reclosing times. Therefore, the larger is the reclosing time; the lower is the retained voltage during the simulation. For this simulation, the feeder loads value has been set to $64 \mathrm{~kW}$ and IM running empty at the time the fault occurs.

\section{3) Voltage sag recovery}

It is worth noting that, as expected, the recovery takes place for all phases at the same instant, $t=1.63$ when the $C B$ recloses the circuit, however, the voltage amplitude is not absolutely recovered until $80 \mathrm{~ms}$ after it. Therefore, it has been demonstrated the fact that to fully define the recovery process of this voltage sag approach, it has to be done with two steps, the first when the CB recloses de circuit and the second when the voltage reaches the pre-fault value.

\section{Conclusion}

This paper has presented a new voltage sag typology, both simulations and real recorded events have demonstrated the proposed analytical expression. The results have proven the dependability of the model adopted as well as the appropriateness of this new voltage sag approach. Overall, this study has enhanced the present research towards PQ disturbances. Furthermore, this study reliably demonstrates the fact that further immunity tests are required in order to observe its effects on loads.

\section{Acknowledgement}

The authors wish to acknowledge the financial support and the willingness of sharing field measurements by the Spanish DSO Electrica Serosense Distribuidora. The authors would also like to thank the Catalonian College of Engineers for the grant received.

\section{References}

[1] M. H. Bollen, Understanding Power Quality Problems. 1999

[2] J. A. Martinez and J. Martin-Arnedo, "Voltage Sag Studies in Distribution Networks-Part II: Voltage Sag Assessment," IEEE Trans. Power Deliv., vol. 21, no. 3, pp. 1679-1688, 2006.

[3] Z. Wang, X. Wang, and C. Y. Chung, "An analytical method for calculating critical voltage sag clearance time of induction motors," IEEE Trans. Power Deliv., vol. 27, no. 4, pp. 2412-2414, 2012

[4] T. Tayjasanant, C. Li, and W. Xu, "A Resistance SignBased Method for Voltage Sag," vol. 20, no. 4, pp. 2544-2551, 2005.

[5] J. Pedra, S. Bogarra, F. Córcoles, L. Monjo, and A. Rolán, "Testing of three-phase equipment under voltage sags," IET Electr. Power Appl., vol. 9, no. 4, pp. 287296, 2015.

[6] L. Guasch, F. Córcoles, and J. Pedra, "Effects of symmetrical and unsymmetrical voltage sags on induction machines," IEEE Trans. Power Deliv., vol. 19, no. 2, pp. 774-782, 2004.

[7] M. H. J. Bollen, "Characterisation of voltage sags experienced by three-phase adjustable-speed drives," IEEE Trans. Power Deliv., 1997.

[8] M. H. J. Bollen, "Assessment of the number of voltage sags experienced by a large industrial customer," IEEE Trans. Ind. Appl., 1997.

[9] J. Martinez-Velasco and J. Martin-Arnedo, "EMTP model for analysis of distributed generation impact on voltage sags," IET Gener. Transm. Distrib., vol. 1, no. 1, pp. 112-119, 2007.

[10] S. Rönnberg and M. Bollen, "Power quality issues in the electric power system of the future," Electr. J., 2016.

[11] CIGRE/CIRED/UIE Joint Working Group C4.110, "Voltage Dip Immunity of Equipment and Installations," CIGRE Publ., no. April, pp. 1-18, 2010.

[12] M. H. J. Bollen, "Influence of motor reacceleration on voltage sags," IEEE Trans. Ind. Appl., vol. 31, no. 4, pp. 667-674, 1995.

[13] M. Falahi, K. L. Butler-Purry, and M. Ehsani, "Induction motor starting in islanded microgrids," IEEE Trans. Smart Grid, 2013.

[14] L. Zhang and M. H. J. Bollen, "Characteristic of voltage dips (sags) in power systems," IEEE Trans. Power Deliv., vol. 15 , no. 2, pp. 827-832, 2000

[15] Y. Wang, A. Bagheri, M. H. J. Bollen, and X. Y. Xiao, "Single-Event Characteristics for Voltage Dips in Three-Phase Systems," IEEE Trans. Power Deliv., vol. 32, no. 2, pp. 832-840, 2017.

[16] M. H. J. Bollen, S. Bahramirad, and A. Khodaei, "Is there a place for power quality in the smart grid?," in Proceedings of International Conference on Harmonics and Quality of Power, ICHQP, 2014.

[17] M. H. J. Bollen, J. Zhong, F. Zavoda, J. Meyer, A. McEachern, and F. Córcoles López, "Power quality aspects of smart grids," Int. Conf. Renew. Energies Power Qual. (ICREPQ'10), Granada 23-25 March, 2010, 2010

[18] Di. Chakravorty, B. Chaudhuri, and S. Y. R. Hui, "Rapid Frequency Response from Smart Loads in Great Britain Power System," IEEE Trans. Smart Grid, vol. 8 , no. 5, pp. 2160-2169, 2017.

[19] IEEE Standards Coordinating Committee 21, IEEE Application Guide for IEEE Std $1547^{T M}$, IEEE Standard for Interconnecting Distributed Resources with Electric Power Systems, no. April. 2009.

[20] A. R. Blanco, "Estudio del efecto de los huecos de tension en el generador de induccion doblemente alimentado," UPC, 2012.

[21] M. H. J. Bollen, "Voltage recovery after unbalanced and balanced voltage dips in three-phase systems," IEEE Trans. Power Deliv., vol. 18, no. 4, pp. 1376-1381, 2003.

[22] J. A. Martinez-Velasco and J. Martin-Arnedo, "Calculation of Voltage Sag Indices for Distribution Networks," pp. 1-6, 2005. 